\title{
Jurist-Diction
}

Volume 2 No. 5, September 2019

Histori artikel: Submit 28 Juli 2019; Diterima 23 Agustus 2019; Diterbitkan online 1 September 2019.

\section{Tinjauan Legalitas Transaksi Bitcoin Di Indonesia}

\author{
Keisya Naomi Natalia Nababan \\ keisya.naomi@gmail.com \\ Universitas Airlangga
}

\begin{abstract}
Bitcoin is a payment instrument invented and developed not under any authority. The use of Bitcoin is growing year by year with high exchange rates. In 2018, the value of Bitcoin reached USD 19,783.06 per 1 (one) Bitcoin where the value is volatile because the number of Bitcoin is limited, which only reaches a maximum of 21 million (twenty-one million). Regarding the popularity of Bitcoin, Central Bank of Indonesia issued a statement that Bitcoin is not a legitimate payment instrument and the risk of use will be borne by the user. This research discusses the validity of transactions that use Bitcoin for the payment instrument. The author will review the characteristics of Bitcoin as virtual money, Bitcoin as a currency, and the validity of Bitcoin transactions related to the terms of the agreement based on the Indonesian Civil Code. Transactions using Bitcoin are contrary to the applicable laws and regulations. In answering to this issue, the author uses a normative juridical approach by conducting research that is examined from the applicable legal sources by the conceptual approach and the legislative approach.
\end{abstract}

Keywords: Bitcoin; Virtual Money; Payment Instrument.

\begin{abstract}
Abstrak
Bitcoin adalah salah satu macam alat bayar yang diciptakan dan dikembangkan tidak di bawah otoritas apapun. Penggunaan Bitcoin berkembang dari tahun ke tahun dengan nilai pertukaran yang tinggi. Bahkan pada tahun 2018, nilai Bitcoin mencapai USD 19,783.06 per 1 (satu) Bitcoin yang mana nilai tersebut bersifat fluktuatif karena jumlah Bitcoin tersebut terbatas yakni hanya mencapai maksimal 21 juta (dua puluh satu juta). Terhadap popularitas Bitcoin tersebut, Bank Indonesia mengeluarkan pernyataan bahwa Bitcoin bukanlah alat pembayaran yang sah dan risiko penggunaan akan ditanggung sendiri oleh pengguna. Penelitian ini membahas mengenai keabsahan transaksi yang menggunakan Bitcoin jika alat bayarnya tersebut tidak sah. Penulis akan meninjau karakteristik Bitcoin sebagai uang virtual, Bitcoin sebagai mata uang dalam berbagai sisi, serta keabsahan transaksi Bitcoin jika dikaitkan dengan syarat perjanjian berdasarkan Kitab Undangundang Hukum Perdata. Terhadap transaksi menggunakan Bitcoin tersebut bertentangan dengan peraturan perundang-undangan yang berlaku. Dalam menjawab isu hukum yang ada, Penulis menggunakan pendekatan yuridis normatif dengan melakukan penelitian yang dikaji dari sumber hukum yang berlaku dengan menggunakan metode pendekatan konseptual dan pendekatan Undangundang.
\end{abstract}

Kata Kunci: Bitcoin; Uang Virtual; Alat Bayar.

\section{Pendahuluan}

Perkembangan internet dan teknologi di dunia berkembang sangat pesat dalam berbagai hal khususnya dalam bidang keuangan dan produk-produknya. Pengembangan financial technology pada dasarnya mempunyai tujuan untuk memudahkan masyarakat dalam menggunakan produk keuangan dan 
mempermudahkan transaksi. Financial technology juga menguntungkan karena mempunyai sifat fleksibel karena hanya sedikit peraturan yang melingkupinya sehingga tidak kaku seperti bisnis konvensional lainnya. Perkembangan teknologi tersebut juga hadir dalam hal alat pembayaran yang ada yang bertujuan untuk memudahkan masyarakat dalam pemakaiannya.

Uang sebagai alat pembayaran pada awalnya tercipta dari sistem pertukaran barang dengan barang yang dikenal dengan sistem barter pada zaman primitive. Lalu karena kondisi masyarakat kian meninggi, sistem barter barang semakin sulit digunakan karena pola pertukaran yang kurang tepat. Pada akhirnya masyarakat setuju untuk mempergunakan alat tukar agar digunakan di perdagangan dengan bentuk berbeda-beda yang berlaku di cakupan wilayah tertentu saja sesuai dengan kebutuhan negara masing-masing. ${ }^{1}$

Uang sebagai alat tukar telah mempunyai nilai benda yang khusus yang dapat digunakan untuk membayar barang dan jasa, namun jika mendefinisikan uang sematamata sebagai mata uang terlalu sederhana bagi ekonom karena banyak hal yang dapat dijadikan sebagai uang, sebagai contohnya cek dan tabungan dalam arti luas. Maka tidak ada definisi tunggal, definisi yang benar-benar tepat dari uang atau uang ydar, bahkan bagi ekonom sekalipun. ${ }^{2}$ Para ekonom mengatakan bahwa The pieces of this paper have value because everyone thinks they have value. ${ }^{3}$ Maka dari itu sejarah uang diakui karena setiap orang menganggap uang berfungsi sebagai alat tukar.

Alat pembayaran dikenal dalam bentuk tunai dan non-tunai. ${ }^{4}$ Untuk alat pembayaran non-tunai adalah salah satu produk perkembangan dari financial technology sendiri dan dapat berupa uang elektronik dan uang virtual. Yang menjadi perbedaan uang elektronik dan virtual adalah pembuatan dan pencatatan

1 Solikin dan Suseno, Uang: Pengertian, Penciptaan dan Peranannya dalam Perekonomian (Pusat Pendidikan dan Studi Kebanksentralan (PPSK) Bank Indonesia 2002).[4-8].

2 Frederic S. Mishkin, Ekonomi Uang, Perbankan, dan Pasar Keuangan, 8th ed. (Penerbit Salemba Empat 2008).[68].

3 Milton Friedman dan Rose D. Friedman, Free to Choose: A Personal Statement (Harcourt Brace Jovanovich 1980).[249].

4 Bank Indonesia, 'Sistem Pembayaran di Indonesia', (Bank Indonesia, 2011) <https://www. bi.go.id/id/sistem-pembayaran/di-indonesia/Contents/Default.aspx> accessed 15 Mei 2018. 
transaksinya. Uang elektronik transaksinya tercatat di server pusat yakni dapat diatur oleh Bank Indonesia dan berbasis server dan chip (seperti Flazz BCA, Brizzi BRI, eMoney Mandiri, TapCash BNI, dan sebagainya), sedangkan uang virtual seperti Bitcoin, Litecoin, dan Ethereum, seluruh sistemnya berdasar kepada blok atau blockchain dan transaksinya tercatat di jaringan desentralisasi blockchain, jadi setiap orang dapat mengakses rantai blok ini dan masyarakat dapat terhubung di seluruh dunia. Bank Indonesia juga menyampaikan bahwa uang elektronik tidak termasuk uang virtual. ${ }^{5}$

Jaringan blockchain adalah salah satu bagian dari financial technology. Blockchain mencakup semua transaksi cryptocurrency, dan yang paling menonjol adalah Bitcoin. Blockchain adalah catatan publik yang hanya ada di dunia digital sehingga orang yang mempunyainya tidak mendapatkan uang atau koin secara fisik. Orang bisa mendapatkan cryptocurrency di dunia digital baik dengan menerima, melakukan trading, atau mining. Tidak ada bank sentral di Blockchain karena transaksi dikelola oleh pengguna-pengguna yang telah membuat catatan tersebut. ${ }^{6}$

Bitcoin dalam hal tersebut menggunakan teknologi P2P (teknologi peerto-peer) tanpa otoritas pusat. Maka dari itu fungsi seperti penerbitan, proses transaksi dan verifikasi dilakukan secara kolektif oleh jaringan tanpa pengawasan dari lembaga pusat. P2P adalah salah satu model jaringan komputer yang terdiri dari dua atau beberapa komputer, dimana setiap station atau komputer yang terdapat di dalam lingkungan jaringan tersebut bisa saling berbagi. Jaringan ini memudahkan pengguna dalam bertransaksi secara langsung tanpa memerlukan jasa dari pihak ketiga seperti misalnya bank. ${ }^{7}$ Algoritma, program komputer, dan komunitas pengguna yang memungkinkan sistem cryptocurrency seperti Bitcoin untuk dikembangkan dan dioperasikan sekarang berfungsi sebagai platform untuk

\footnotetext{
5 Peraturan Bank Indonesia No. 18/40/2016 Tentang Penyelenggaraan Pemrosesan Transaksi Pembayaran

6 Stephen Fleming, Blockchain Technology: Introduction to Blockchain Technology and its impact on Business Ecosystem (Primedia eLaunch LLC 2017).[3].

7 Fatimah Salsabila, 'Hukumpedia: "Bitcoin dalam Perspektif Yuridis di Indonesia', <http:// www.hukumonline.com/berita/baca/lt5a4f42e32269a/Bitcoin-dalam-perspektif-yuridis-di-indonesia-oleh--fatimah-salsabila> diakses pada tanggal 14 Maret 2018.
} 
mendukung hubungan dan aktivitas komersial yang terus berkembang disamping fungsi pertukaran nilai ekonomis yang ditawarkan oleh digital asli. Aplikasi mata uang platform yang ditawarkan oleh Bitcoin dan sistem cryptocurrency lainnya memungkinkan pembuatan, operasi, dan pengelolaan sistem buku besar cryptography transaksi terdistribusi yang bersifat global dan memungkinkan semua node dalam jaringan untuk berbagi informasi riwayat transaksi yang terakumulasi dari waktu ke waktu. ${ }^{8}$ Maka dari itu, Hal ini menjadi keuntungan bagi masyarakat dimana setiap orang dapat mempunyai catatan blockchain tersendiri tanpa ada suatu badan atau individu yang mengontrolnya.

Individu atau badan yang mengontrol Bitcoin menyimpan Bitcoin menggunakan wallet. Wallet adalah aplikasi yang menyediakan primary user interface. Wallet mengkontrol seluruh akses dana dari pengguna, mengelola kunci dan alamat, melacak saldo, membuat dan menandatangani transaksi. Dompet hanya berisi kunci (key), koin tetap dicatat di dalam blockchain pada jaringan Bitcoin. Pengguna mengendalikan koin di jaringan dengan menandatangani transaksi dengan kunci di wallet. ${ }^{9}$

Dalam halnya penggunaan uang virtual semakin meningkat karena kemudahan transaksi yang tersedia, Bank Indonesia sebagai bank sentral di Indonesia yang memiliki wewenang untuk mengatur penggunaan alat pembayaran tersebut kemudian mengeluarkan pernyataan yakni Pernyataan Bank Indonesia Terkait Bitcoin dan Virtual Currency Lainnya pada tahun 2014 dengan No. 16/6/Dkom yang pada pokoknya menyatakan bahwa Bitcoin dan virtual currency lainnya bukan alat pembayaran yang sah di Indonesia, dan risiko penggunaannya ditanggung sendiri oleh pengguna. Terdapat pula dalam pernyataan dalam Undang - undang No. 7 Tahun 2011 tentang Mata Uang bahwa Indonesia hanya mengakui Rupiah sebagai alat tukar yang sah. Bank Indonesia

\footnotetext{
8 Jeffrey H. Matsuura, Digital Currency: An International Legal and Regulatory Compliance Guide (Bentham Science Publishers Ltd. 2016).[88].

9 Andreas M. Antonopoulos, Mastering Bitcoin: Programming the Open Blockchain (O’Reilly Media, Inc. 2017).[5].
} 
kemudian membuat pernyataan pers kembali pada tahun 2018 dengan judul "Bank Indonesia Memperingatkan Kepada Seluruh Pihak Agar Tidak Menjual, Membeli atau Memperdagangkan Virtual Currency" dengan No. 20/4/DKom, bahwa Bank Indonesia menegaskan bahwa sebagai otoritas sistem pembayaran, Bank Indonesia melarang penggunaan dan penyelenggaraan Bitcoin dan bentuk virtual currency lainnya di Indonesia.

\section{Karakteristik Bitcoin Sebagai Uang Virtual}

Bank Indonesia kemudian memperjelas lagi definisi mengenai uang virtual dalam penjelasan Pasal 34 huruf a Peraturan BI 18/2016, yaitu yang dimaksud dengan uang virtual adalah uang digital yang diterbitkan oleh pihak selain otoritas moneter yang diperoleh dengan cara mining, pembelian, atau transfer pemberian (reward) antara lain Bitcoin, BlackCoin, Dash, Dogecoin, Litecoin, Namecoin, Nxt, Peercoin, Primecoin, Ripple, dan Ven. Tidak termasuk dalam pengertian uang virtual adalah uang elektronik. ${ }^{10}$

Bitcoin yang dalam hal ini dikategorikan sebagai uang virtual mempunyai beberapa karakteristik secara umum, yaitu:

\section{Blockchain}

Sistem blockchain diperkenalkan bersamaan dengan terciptanya Bitcoin pada tahun 2009. Blockchain adalah dasar dari semua transaksi Bitcoin yang pernah dijalankan. Setiap node (komputer pengguna) secara lengkap memiliki salinan blockchain yang diunduh secara otomatis ketika pengguna bergabung dengan jaringan Bitcoin. Blockchain memiliki informasi lengkap tentang alamat dan saldo dari transaksi pertama yang pernah dilakukan ke blok yang baru saja selesai. Blockchain dapat disebut sebagai catatan publik berarti bahwa mudah untuk melihat transaksi yang berkaitan dengan alat Bitcoin tertentu. Bitcoin dalam hal ini berdiri dengan mekanisme trustless di semua jaringan, pengguna dapat mempercayai sistem catatan publik yang disimpan diseluruh dunia pada node

\footnotetext{
${ }_{10}$ Penjelasan Pasal 34 huruf a, Peraturan Bank Indonesia Nomor 18/40/PBI/2016 Tentang Penyelenggaraan Pemrosesan Transaksi Pembayaran
} 
yang terdesentralisasi tanpa harus dengan harus membangun dan memelihara kepercayaan dengan pihak lawan transaksi (orang lain) atau perantara pihak ketiga (seperti bank). ${ }^{11}$ Transaksi Bitcoin tersebut akan ditambahkan ke blockchain dengan permanen dan dapat diakses oleh siapapun.

2. Peer-to-peer (P2P)

Implementasi jaringan $\mathrm{P} 2 \mathrm{P}$ dalam Bitcoin berarti jaringan tersebut menciptakan struktur di mana tidak ada server terpusat, seluruh anggota jaringan tersebut berkedudukan setara. Karena tidak memiliki bank sentral tersebut, Bitcoin pun mengandalkan jaringan P2P ini untuk menjalankan sistemnya. Dengan P2P, para anggota pengguna akan diberikan informasi berupa seluruh transaksi Bitcoin yang sama di seluruh komputer milik pengguna Bitcoin di seluruh dunia. ${ }^{12}$ Maka dari itu seluruh sejarah transaksi Bitcoin akan tersedia untuk umum. Hal ini juga diperlukan untuk memvalidasi transaksi untuk mencegah pengeluaran ganda (double spend) dalam ketiadaan dari otoritas pusat.

3. Desentralisasi

Sebagai uang virtual, Bitcoin mempunyai konsep transaksi yang berbeda dengan mata uang lainnya. Sebagian besar mata uang memiliki jenis transaksi yang disebut sebagai triangle type of transaction, dimana bank memiliki peran penting untuk menjadi perantara antar pihak. Tipe transaksi triangle biasanya disebut sebagai sentralisasi dimana bank berperan dalam perantara keuangan. Sedangkan konsep desentralisasi yang dimiliki oleh Bitcoin sebagai uang virtual hanya membutuhkan dua pihak yang saling setuju tanpa perantara pihak lain. ${ }^{13}$ Hal tersebut dapat dilihat seperti gambar berikut ini: $:^{14}$

${ }^{11}$ Melanie Swan, Blockchain (O’Reilly Media, Inc. 2015).[x].

12 Dimaz Ankaa Wijaya, et al., Mengenal Bitcoin dan Cryptocurrency (Puspantara 2016). [23-24].

13 Mariske Myeke Tampi, 'Legal Protection For Bitcoin Investors In Indonesia: To Move Beyond The Current Exchange System' (2017) 1 Jurnal Hukum \& Pembangunan 47.[87].

${ }^{14}$ Mariske Myeke Tampi, Loc. Cit. 

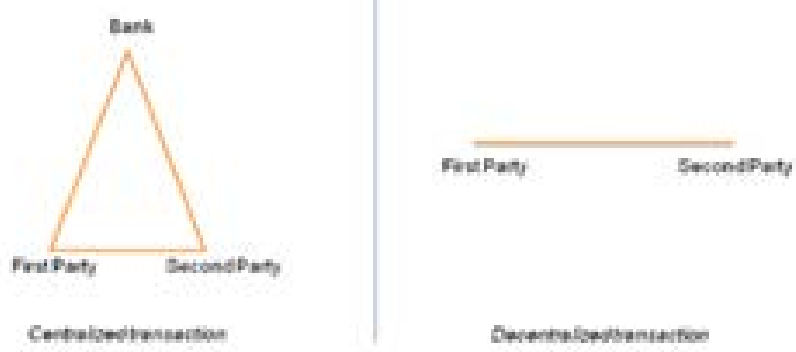

Gambar 1. Triangle type of transaction (sumber: Mariske Myeke Tampi, Loc.Cit)

Perkembangan transaksi digital selama ini sangat berkembang seperti penggunaan Visa, MasterCard, Paypal, dan Western Union yang dikelola oleh pihak ketiga untuk melakukan fungsi pengelolaan data nasabah. Namun dengan konsep desentralisasi yang ada di dalam Bitcoin ini kemudian memungkinkan transaksi yang dilakukan oleh pengguna tidak tergantung oleh pihak ketiga. Hal ini dimungkinkan karena bitcoin menggunakan teknologi jaringan peer-to-peer dalam mengelola setiap transaksi yang terjadi. ${ }^{15}$

\section{Anonimitas}

Pengguna Bitcoin dalam hal ini dapat mengambil langkah untuk melindungi identitas pengguna dengan lebih baik, pengguna dapat menghindari mengungkapkan informasi pengidentifikasi apa pun terkait dengan identitas mereka. Jadi dalam penggunaannya, pengguna Bitcoin dapat tidak memberikan informasi apapun mengenai datanya sehingga walaupun seluruh transaksi di Bitcoin dapat dilihat oleh setiap anggota pengguna, namun akibat dari anonimitas para pengguna tidak dapat mengklarifikasi transaksi tersebut milik siapa dan dikirimkan kepada siapa. Hal tersebut kemudian membuat pengguna Bitcoin menyalahgunakan sistem tersebut yang dengan adanya sifatnya anonimitas dapat membuat tindakan kejahatan seperti jual-beli narkotika, pencucian uang, dan tindakan lainnya menjadi lancar dan tidak teridentifikasi.

\footnotetext{
15 Ferry Mulyanto, 'Pemanfaatan Cryptocurrency Sebagai Penerapan Mata Uang Rupiah Kedalam Bentuk Digital Menggunakan Teknologi Bitcoin' (2015) 4 Indonesian Journal on Networking and Security.[22].
} 


\section{Analisa Bitcoin Sebagai Mata Uang}

Uang menurut Undang-Undang Nomor 7 Tahun 2011 tentang Mata Uang adalah alat pembayaran yang sah. Sedangkan yang dimaksud dengan mata uang adalah uang yang dikeluarkan oleh Negara Kesatuan Republik Indonesia yang selanjutnya disebut Rupiah. ${ }^{16}$ Menurut definisi yang telah disebutkan, dapat disimpulkan bahwa Rupiah adalah alat pembayaran yang sah di Indonesia. Terhadap Bitcoin yang merupakan uang virtual, berikut beberapa tinjauan menurut berbagai aspek:

\section{Tinjauan Bitcoin sebagai Mata Uang dari Fungsi}

Ekonom secara umum menjabar fungsi-fungsi sesuatu dapat disebut sebagai uang, yaitu alat tukar (medium of exchange), a unit of account, and a store of value. ${ }^{17}$ - Bitcoin sebagai Alat Tukar (Medium of Exchange)

Sebagai medium of exchange, Bitcoin harus diterima sebagai pembayaran untuk barang atau jasa yang berjumlah besar, ataupun aset lainnya. Dalam hal ini, pengguna Bitcoin harus meyakini bahwa Bitcoin dapat diterima orang lain sebagai pembayaran untuk suatu objek layaknya uang kertas yang diterima oleh orang lain seperti alat pembayaran. Dalam singkatnya, setiap orang menerima sesuatu sebagai uang karena orang lain juga menerimanya. Potongan kertas yang kita miliki sekarang juga memiliki nilai karena semua orang berpikir kertas tersebut mempunyai nilai berdasarkan pengalamannya. ${ }^{18}$ Tidak seperti uang kertas biasa, bagaimanapun, Bitcoin tidak didukung oleh entitas yang berdaulat dan mengandalkan pihak agen swasta untuk melayani sebagai alat tukar.

Pada tahun 2014 para ekonom sepakat bahwa Bitcoin masih memiliki jumlah pengguna yang sedikit, yang membuatnya jauh dari pengertian alat tukar yang universal. Penentuan Bitcoin sebagai alat tukar dapat dianalisa dari banyaknya pengguna Bitcoin yang saat ini juga sudah mencapai 24,189,257

\footnotetext{
${ }^{16}$ Undang-Undang Nomor 7 Tahun 2011 Tentang Mata Uang, Pasal 1 angka 2

${ }^{17}$ Frederic S. Mishkin, Loc.cit.

${ }_{18}$ Milton Friedman dan Rose D. Friedman, Op. Cit.[249].
} 
pengguna dengan peningkatan yang cukup signifikan. ${ }^{19}$ Dalam jumlah tersebut, masyarakat telah menganggap Bitcoin sendiri sebagai alat tukar untuk perolehan barang dan jasa.

- Bitcoin sebagai Satuan Hitung (A Unit of Account)

Bitcoin dapat dikatakan sebagai satuan hitung yang tidak baik. Meskipun Bitcoin dapat ditukar dengan berbagai barang dan jasa, dalam mendapatkan harga beberapa orang sulit untuk menentukan satuan tersebut secara langsung dalam Bitcoin. Bitcoin bukan satuan hitung yang baik karena volatilitasnya yang tinggi. Pendukung Bitcoin berpendapat bahwa jika harga Bitcoin stabil maka semakin banyak pedagang akan mulai mengutip harga mereka dengan mudah dalam Bitcoin. ${ }^{20}$

- Bitcoin sebagai Alat Penyimpan Nilai (A Store of Value)

Dalam hal ini uang harus dapat digunakan untuk mentransfer daya beli dari masa sekarang ke masa depan. Kritik utama yang didapat oleh Bitcoin sebagai penyimpan nilai adalah volatilitasnya. Gambar diatas menunjukkan sejarah harga Bitcoin sejauh ini. Di harga tertinggi Bitcoin pernah mencapai US \$ 19,499 pada bulan Desember 2017 dan terus meningkat dan menurun seusai dengan masanya, bahkan pada awal April 2018 nilai Bitcoin mencapai US \$ 6,794. ${ }^{21}$ Ada beberapa kesepakatan antara ekonom bahwa Bitcoin dipandang lebih sebagai investasi berisiko dalam model bisnis baru daripada sebagai penyimpan nilai yang stabil. ${ }^{22}$

\section{Tinjauan Bitcoin sebagai Mata Uang dari Syarat Uang}

Menurut Prathama Rahardja dalam bukunya berjudul 'Uang \& Perbankan', benda dapat dikategorikan sebagai uang jika benda tersebut telah memenuhi syaratsyarat berikut:

1. benda itu harus diterima secara umum (acceptability);

2. memiliki nilai yang cenderung stabil (stability of value),

\footnotetext{
${ }^{19}$ Blockchain, 'Blockchain Wallet Users' (Blockchain info, 2018) <https://blockchain.info/ charts/my-wallet-n-users?timespan=all> accessed 16 April 2018.

${ }_{20}$ Pedro Franco, Understanding Bitcoin: Cryptography, Engineering, and Economics (John Wiley \& Sons Ltd. 2015).[32].

${ }^{21}$ Blockchain, 'Market Price', (Blockchain info 2018) <https://blockchain.info/charts/market-price?timespan=2years $>$ accessed 17 April 2018.

${ }^{22}$ Pedro Franco, Op.Cit.[7].
} 
3. ringan dan mudah dibawa (portability);

4. tahan lama (durability);

5. Kualitas cenderung sama (uniformity);

6. jumlahnya terbatas dan tidak mudah dipalsukan (scarity);

7. mudah dibagi tanpa mengurangi nilai (divisibility). ${ }^{23}$

Berikut perbandingan uang konvensional dan Bitcoin yang ditinjau berdasarkan syarat uang: ${ }^{24}$

Tabel 1. Tabel Perbandingan Bitcoin dan Uang Konvensional Ditinjau dari Syarat Uang

\begin{tabular}{|c|c|c|c|}
\hline No & Syarat Uang & Uang Konvensional & Bitcoin \\
\hline 1 & $\begin{array}{l}\text { Benda tersebut diter- } \\
\text { ima secara umum }\end{array}$ & $\begin{array}{l}\text { Uang diterima secara umum } \\
\text { sebagai alat tukar yang sah na- } \\
\text { mun penggunaannya terbatas } \\
\text { pada wilayah negara tertentu. }\end{array}$ & $\begin{array}{l}\text { Bitcoin belum diterima secara } \\
\text { umum karena penggunaannya } \\
\text { terbatas menggunakan internet. } \\
\text { Beberapa negara juga masih } \\
\text { mengkaji Bitcoin sebagai uang } \\
\text { virtual yang berlaku di negaran- } \\
\text { ya. }\end{array}$ \\
\hline 2 & $\begin{array}{l}\text { Memiliki nilai yang } \\
\text { cukup stabil }\end{array}$ & $\begin{array}{l}\text { Memiliki nilai yang cukup sta- } \\
\text { bil karena diawasi oleh lemba- } \\
\text { ga moneter di suatu negara. }\end{array}$ & $\begin{array}{l}\text { Memiliki nilai yang tidak stabil } \\
\text { (volatilitas tinggi) dan cenderung } \\
\text { fluktuasi. }\end{array}$ \\
\hline 3 & $\begin{array}{l}\text { Ringan dan mudah } \\
\text { dibawa }\end{array}$ & $\begin{array}{l}\text { Ringan dan mudah dibawa na- } \\
\text { mun dalam jumlah yang besar } \\
\text { sulit untuk dibawa. }\end{array}$ & $\begin{array}{l}\text { Ringan dan mudah dibawa kare- } \\
\text { na di berada di dalam e-wallet. }\end{array}$ \\
\hline 4 & Tahan lama & Tahan lama tapi dapat rusak. & Tahan lama tapi dapat kena virus. \\
\hline 5 & $\begin{array}{l}\text { Kualitas cenderung } \\
\text { sama }\end{array}$ & Kualitas cenderung sama. & $\begin{array}{l}\text { Fisik berada didalam e-wallet se- } \\
\text { hingga tidak mempunyai bentuk } \\
\text { fisik. }\end{array}$ \\
\hline 6 & $\begin{array}{l}\text { Jumlah terbatas dan } \\
\text { tidak mudah dipal- } \\
\text { sukan }\end{array}$ & $\begin{array}{l}\text { Jumlah terbatas dan tidak mu- } \\
\text { dah dipalsukan. }\end{array}$ & $\begin{array}{l}\text { Untuk Bitcoin jumlah sudah } \\
\text { ditentukan hanya sejumlah } \\
\text { 21.000.000.000 dan tidak mudah } \\
\text { dipalsukan karena ada kode-kode } \\
\text { tertentu untuk mengidentifikasin- } \\
\text { ya. }\end{array}$ \\
\hline 7 & $\begin{array}{l}\text { Mudah dibagi tanpa } \\
\text { mengurangi nilai }\end{array}$ & $\begin{array}{l}\text { Mudah dibagi tanpa mengu- } \\
\text { rangi nilai. }\end{array}$ & $\begin{array}{l}\text { Mudah dibagi tanpa mengurangi } \\
\text { nilai. }\end{array}$ \\
\hline
\end{tabular}

Sumber: Sigit Somadiyono, Loc.cit

${ }^{23}$ Prathama Rahardja, Uang \& Perbankan (Rineka Cipta 1987).[6].

${ }^{24}$ Sigit Somadiyono, 'Relevansi UU No. 7 Tahun 2011 Tentang Mata Uang Dengan Fenomena Munculnya Mata Uang Virtual, Studi Kasus Fenomena Bitcoin Di Indonesia’ (2014) 14 Jurnal Ilmiah Universitas Batanghari Jambi.[67-68]. 


\section{Tinjauan Bitcoin dari Jenis Uang}

Jika sebelumnya telah disebutkan mengenai fungsi dan syarat uang, dalam penggunaan uang, otoritas yang berwenang yang mempunyai wewenang untuk mengeluarkan dan mengedarkann uang. Adapun berdasarkan pengelompokan peranan proses penciptaan uang ada 3 (tiga) pelaku utama yaitu otoritas moneter, bank umum, dan masyarakat atau sektor swasta domestik. Dapat disederhanakan bahwa otoritas moneter menciptakan uang kartal, sementara bank umum menciptakan uang giral dan uang kuasi. Masyarakat akan menggunakan uang yang diciptakan oleh otoritas moneter dan bank umum tersebut untuk melaksanakan kegiatan ekonomi. ${ }^{25}$

- Uang kartal

Uang kartal terdiri dari uang logam dan uang kertas di Indonesia yang sederhananya dipegang oleh masyarakat sehari-hari. Menurut Pasal 26 ayat (1) Undang-Undang Bank Sentral No. 14 Tahun 1968, Bank Indonesia mempunyai hak tunggal untuk mengeluarkan uang logam dan uang kertas, hal tersebut kemudian disebut dengan hak oktroi. ${ }^{26}$

Dalam hal ini, Bitcoin bukanlah jenis uang yang dibuat oleh otoritas moneter ataupun bank umum, Bitcoin juga bukan merupakan uang kartal yang merupakan alat pembayaran yang sah sesuai dengan peraturan perundang-undangan.

\section{- Uang Giral}

Penciptaan uang giral adalah karena semakin mendesaknya kebutuhan masyarakat akan adanya alat tukar yang praktis, mudah, dan aman. Jadi uang giral dalam perkembangannya merupakan uang yang disimpan oleh masyarakat dalam bentuk deposit atau simpanan dan dapat ditarik kapan saja sesuai dengan kebutuhan. Namun dalam penggunaannya terdapat beberapa kekurangan dari uang giral, karena sebenarnya uang kartal yang merupakan alat bayar yang sah dan wajib digunakan oleh masyarakat dalam melakukan transaksi jual beli dalam kehidupan sehari-hari, maka dari itu penggunaan uang giral tidak sepenuhnya

\footnotetext{
${ }^{25}$ Solikin dan Suseno, Op.Cit.[17].

${ }^{26}$ Geri Ahmadi, Seluk Beluk Uang (Yudhistira 2007).[19].
} 
dipakai oleh semua orang karena penerimaannya juga tergantung dari penjualnya. ${ }^{27}$

Penciptaan uang giral oleh bank dilakukan dengan cara memberikan pinjaman yang tidak dibebankan dari saldo (bank) nasabah. Artinya, saldo nasabah tetap akan utuh walaupun bank memberikan fasilitas kredit, dan sebaliknya nasabah tetap memilki hak terhadap setiap penarikan uangnya selama saldo di bank mencukupi. Hal ini dilakukan karena dalam praktik perbankan tidak semua nasabah menarik saldonya pada saat yang sama. Karena jumlah permintaan kredit lebih besar dari jumlah saldo nasabah, maka bank bersedia melepaskan kredit yang lebih besar dari saldo nasabah dengan cara menciptakan uang giral melalui rekening koran. Dengan demikian uang kartal tetap sama, tetapi jumlah uang giral yang diciptakan akan bertambah. ${ }^{28}$

Seiring dengan kemajuan teknologi, khususnya teknologi informasi, mulailah berkembang uang elektronik, pihak yang melakukan transaksi jualbeli atau kegiatan ekonomi lainnya dapat membawa uang elektronik dalam chip based atau server based yang dikeluarkan oleh berbagai pihak penyelenggara uang elektronik yang terdaftar dan dibawah izin yang ditentukan. Dengan ini transaksipun semakin mudah dengan hanya melakukan pembayaran melalui kartu kredit, transfer antar rekening, yang saat ini juga dapat dilakukan melalui sms, telepon seluler ataupun internet. Indonesia sejak beberapa tahun lalu telah memulai inisiatif untuk mengkampanyekan penggunaan transaksi nontunai dalam masyarakat alias less cash society. ${ }^{29}$

Pada 14 Agustus 2014, Bank Indonesia meluncurkan program Gerakan Nasional Non Tunai (GNNT) yang bertujuan untuk membuat masyarakat Indonesia mengalihkan kebiasaan bertransaksi menggunakan uang nontunai yang salah satunya adalah melalui uang elektronik. Transaksi nontunai ini mengurangi

\footnotetext{
${ }^{27}$ Fadly Firnandes dan Rosyetti Rahmat, Richard, 'Pengaruh Uang Giral dan Uang Kuasi terhadap Inflasi di Indonesia' (2014) 1 Jom FEKON.[2].

${ }_{28}$ Dr. Thomas Suyatno, M.M., et al., Kelembagaan Perbankan (Gramedia Pustaka Utama, Jakarta 1988).[20-21].

${ }^{29}$ Bank Indonesia, 'Mengurangi Ketergantungan pada Uang Tunai', Gerai Indo Bank Indonesia, Edisi 50 Tahun 5 (Bank Indonesia 2014).[4].
} 
kebutuhan terhadap uang tunai yang membutuhkan biaya dan energi besar untuk mengelolanya. Transaksi non-tunai akan menghindarkan segala kerepotan dalam mengelola uang tunai seperti menghitung, menyortir, menyimpan, dan mendistribusikan uang. ${ }^{30}$ Secara makro uang giral lebih aman karena tidak mempengaruhi jumlah uang kartal. Meskipun pada satu sisi, uang giral mempunyai kelebihan, tetapi pada sisi yang lain juga mempunyai sisi yang lemah, yakni uang giral bukanlah alat pembayaran yang salah dan wajib diterima oleh siapa saja, masih ada pihak-pihak lain yang berkepentingan yang dapat menolak uang giral dalam transaksinya. ${ }^{31}$

Dalam hal ini Bank Indonesia dengan Peraturan Bank Indonesia Nomor: 11/12/PBI/2009 Tentang Uang Elektronik (Electronic Money) menyatakan bahwa uang elektronik adalah alat pembayaran yang memenuhi unsur-unsur sebagai berikut:

a. diterbitkan atas dasar nilai uang yang disetor terlebih dahulu oleh pemegang kepada penerbit;

b. nilai uang disimpan secara elektronik dalam suatu media seperti server atau chip;

c. digunakan sebagai alat pembayaran kepada pedagang yang bukan merupakan penerbit uang elektronik tersebut;

d. nilai uang elektronik yang disetor oleh pemegang dan dikelola oleh penerbit bukan merupakan simpanan sebagaimana dimaksud dalam undang-undang yang mengatur mengenai perbankan. ${ }^{32}$

Masyarakat sering menyebutkan Bitcoin sebagai uang elektronik karena juga dianggap sebagai less cash. Pada dasarnya Bitcoin bukanlah uang elektronik karena tidak sesuai dengan unsur kumulatif yang dinyatakan oleh Bank Indonesia dalam peraturan di atas. Bitcoin juga tidak diterbitkan menggunakan uang Rupiah yang mana uang elektronik wajib diterbitkan dalam uang Rupiah sesuai dengan ketentuan Bank Indonesia, ${ }^{33}$ melainkan Bitcoin menciptakan mata uang

30 ibid.

${ }^{31}$ Sri Redjeki Hartono, Penulisan Karya Ilmiah Tentang Aspek Hukum Penggunaan Kartu Kredit (Badan Pembinaan Hukum Nasional 1994).[9].

32 Peraturan Bank Indonesia Nomor 11/12/PBI/2009 Tentang Uang Elektronik (Electronic Money), Pasal 1 angka 3.

33 ibid., Pasal 20 
tersendiri yang terdesentralisasi. Dalam hal ini Bitcoin bukanlah termasuk uang giral, karena macam dari uang giral sendiri harus terdaftar dan dibawah izin oleh Bank Indonesia. ${ }^{34}$ Penciptaan uang giral juga oleh bank dan lembaga selain bank yang akan bertindak sebagai prinsipal ${ }^{35}$ yang ditentukan oleh Bank Indonesia sedangkan penciptaan Bitcoin seperti yang ditulis dalam sejarah Bitcoin di atas merupakan ciptaan dari seseorang atau sekelompok orang yang sampai sekarang belum diketahui identitasnya.

- Uang Kuasi

Uang kuasi adalah simpanan masyarakat pada bank umum dalam bentuk deposito berjangka dan tabungan. Uang kuasi dikualifikasikan sebagai uang beredar karena bentuk deposito berjangka ini dapat dicairkan pada saat tertentu menjadi uang tunai oleh pemiliknya. ${ }^{36}$ Uang kuasi dapat berupa surat-surat berharga yang dapat dijadikan sebagai alat pembayaran. Biasanya uang kuasi ini terdiri atas deposito berjangka dan tabungan serta rekening valuta asing milik swasta domestik. Uang kuasi (mencakup tabungan, simpanan berjangka dalam Rupiah dan valas, serta giro dalam valuta asing), dan surat berharga yang diterbitkan oleh sistem moneter yang dimiliki sektor swasta domestik dengan sisa jangka waktu sampai dengan satu tahun. ${ }^{37}$

Dalam hal ini bitcoin sebagai uang virtual juga tidak dapat dijadikan sebagai uang kuasi. Bank Indonesia sendiri sudah membuat pembatasan terhadap jenis uang kuasi. Terhadap giro dalam valuta asing, bitcoin tidak dapat dianggap sebagai valuta asing karena nilai valuta asing adalah mata uang negara lain, sedangkan bitcoin bukanlah mata uang suatu negara dan bitcoin tidak dimiliki oleh negara manapun.

\footnotetext{
34 ibid., Pasal 2 ayat (2)

35 Prinsipal adalah Bank atau Lembaga Selain Bank yang bertanggung jawab atas pengelolaan sistem dan/atau jaringan antar anggotanya, baik yang berperan sebagai penerbit dan/atau $a c$ quirer, dalam transaksi Uang Elektronik yang kerjasama dengan anggotanya didasarkan atas suatu perjanjian tertulis. (Pasal 1 angka 5 Peraturan Bank Indonesia Nomor 11/12/PBI/2009 Tentang Uang Elektronik (Electronic Money))

${ }^{36}$ Prof. Dr. Bustari Muktar, Bank dan lembaga Keuangan Lain (Kencana 2016).[13].

${ }^{37}$ Bank Indonesia, 'Perkembangan Uang Beredar' (www.bi.go.id) < $\underline{\text { https://www.bi.go.id/id/ }}$ publikasi/perkembangan/Default.aspx $>$ accessed 22 April 2018.
} 
Jika disimpulkan dari penjabaran tentang Bitcoin sebagai mata uang sesuai yang telah dijelaskan pada sub bab diatas, maka dapat ditarik kesimpulan:

Tabel 2. Tinjauan Mata Uang terhadap Bitcoin

\begin{tabular}{lll}
\hline No & Tinjauan Mata Uang & Bitcoin \\
\hline 1. & Fungsi Uang & Tidak sesuai \\
2. & Syarat Uang & Sebagian syarat tidak sesuai \\
\hline 3. & Jenis Uang & Tidak sesuai \\
\hline
\end{tabular}

Sumber: diolah dari berbagai sumber

Berdasarkan tinjauan tersebut, dapat dihasilkan analisa bahwa Bitcoin bagi sebagian orang mempunyai tujuan untuk menjadi alat pembayaran namun bukan merupakan mata uang.

\section{Keabsahan Transaksi Bitcoin}

Secara umum perjanjian diatur berdasarkan Pasal 1313 BW yang menyatakan bahwa "Perjanjian adalah suatu perbuatan dengan mana satu pihak atau lebih mengikatkan dirinya terhadap satu orang atau lebih."Terhadap keabsahan perjanjian, dibutuhkan 4 (empat) syarat menurut pasal 1320 KUHPer sebagai berikut: ${ }^{38}$

1. Sepakat mereka yang mengikatkan dirinya;

2. Cakap untuk membuat suatu perjanjian;

3. Mengenai suatu hal tertentu;

4. Suatu sebab yang halal.

Transaksi jual beli yang dilakukan dengan menggunakan Bitcoin didasarkan kepada perjanjian kedua belah pihak. Jika ditinjau lebih lanjut dengan memperhatikan Undang-undang No. 7 Tahun 2011 tentang Mata Uang, dinyatakan bahwa alat bayar yang digunakan untuk setiap transaksi yang mempunyai tujuan pembayaran, atau kewajiban lain yang harus dipenuhi dengan uang, atau transaksi keuangan lainnya yang dilakukan di Wilayah Negara Kesatuan Republik Indonesia wajib menggunakan Rupiah.

Terkait dengan pengaturan tentang Bitcoin, Bank Indonesia pertama kalinya menanggapi Bitcoin dalam Siaran Pers No: 16/ 6 /Dkom berjudul 'Pernyataan Bank

\footnotetext{
${ }^{38}$ Subekti, Hukum Perjanjian (Intermasa 1987).[17].
} 
Indonesia Terkait Bitcoin dan Virtual Currency Lainnya' pada tanggal 6 Februari 2014 yang menyatakan:

"Memperhatikan Undang-undang No. 7 Tahun 2011 tentang Mata Uang serta UU No. 23 Tahun 1999 yang kemudian diubah beberapa kali, terakhir dengan Undang-Undang No. 6 Tahun 2009, Bank Indonesia menyatakan bahwa Bitcoin dan virtual currency lainnya bukan merupakan mata uang atau alat pembayaran yang sah di Indonesia. [penekanan oleh penulis] Masyarakat dihimbau untuk berhati-hati terhadap Bitcoin dan virtual currency lainnya. Segala risiko terkait kepemilikan/penggunaan Bitcoin ditanggung sendiri oleh pemilik/pengguna Bitcoin dan virtual currency lainnya". ${ }^{39}$

Bitcoin pada dasarnya tidak diterima pertukarannya terhadap mata uang Rupiah di bank-bank di Indonesia, hal ini menegaskan bahwa pengedaran Bitcoin dan uang virtual lainnya tidak diatur oleh Pemerintah Indonesia. Dalam hal ini Bank Indonesia adalah satu-satunya lembaga yang berwenang melakukan Pengeluaran, Pengedaran, dan/atau Pencabutan dan Penarikan Rupiah ${ }^{40}$ namun karena Bitcoin bersifat desentralisasi, dimana peran bank tidak dibutuhkan, pengedaran Bitcoin juga bukan merupakan kewenangan Bank Indonesia. Bank Indonesia melalui pernyataan a quo juga telah menegaskan bahwa Bitcoin dan virtual currency lainnya bukan merupakan mata uang atau alat pembayaran yang sah di Indonesia sehingga dilarang peruntukkannya menjadi alat bayar di Indonesia.

Terhadap Bitcoin dan virtual currency lainnya yang bukan merupakan alat pembayaran yang sah di Indonesia dan juga virtual currency tersebut tidak dinaungin oleh Bank Indonesia ataupun lembaga lainnya. Maka dari itu, transaksi menggunakan Bitcoin tidaklah sah karena alat bayarnya yakni Bitcoin itu sendiri tidak sah untuk digunakan maka dari itu tidak terpenuhilah unsur sahnya perjanjian dimana alat bayar yang dipakai tidak sesuai dengan peraturan perundang-undangan yang berlaku.

39 Siaran Pers Pernyataan Bank Indonesia Terkait Bitcoin dan Virtual Currency No. 16/6/ DKom pada tanggal 06-02-2014

40 Undang-Undang Nomor 7 Tahun 2011 Tentang Mata Uang, Pasal 11 ayat (3) 


\section{Kesimpulan}

Dari pernyataan yang telah dinyatakan oleh Bank Indonesia diatas, dapat ditarik satu poin khusus bahwa Indonesia masih belum mengizinkan adanya penggunaan dan penyelenggaraan sistem pembayaran dengan menggunakan Bitcoin. Indonesia masih di dalam sikap menolak Bitcoin karena risiko yang ditimbulkan oleh Bitcoin sangat besar terkhusus volatilitasnya yang tinggi. Bank Indonesia juga menyatakan tidak bertanggung jawab atas kerugian yang disebabkan oleh Bitcoin dan uang virtual lainnya dikarenakan Bitcoin sendiri bukanlah uang yang diterbitkan secara sah di Indonesia.

Transaksi Bitcoin tidak memenuhi unsur syarat sahnya suatu perjanjian karena alat bayarnya yakni Bitcoin itu sendiri tidak sah untuk digunakan sebagai alat bayar yang berlaku di Indonesia, sehingga melanggar salah satu unsur syarat sahnya suatu perjanjian yaitu 'sebab yang halal'. Sehingga dapat disimpulkan bahwa transaksi Bitcoin melanggar ketentuan perundang-undangan yang berlaku di Indonesia.

\section{Daftar Bacaan}

\section{Buku}

Ahmadi, Geri, Seluk Beluk Uang (Yudhistira 2007).

Antonopoulos, Andreas M., Mastering Bitcoin: Programming the Open Blockchain (O’Reilly Media, Inc. 2017).

Fleming, Stephen, Blockchain Technology: Introduction to Blockchain Technology and its impact on Business Ecosystem (Primedia eLaunch LLC 2017).

Franco, Pedro, Understanding Bitcoin: Cryptography, Engineering, and Economics (John Wiley \& Sons Ltd. 2015).

Friedman, Milton dan Rose D. Friedman, Free to Choose: A Personal Statement (Harcourt Brace Jovanovich 1980).

Hartono, Sri Redjeki, Penulisan Karya Ilmiah Tentang Aspek Hukum Penggunaan Kartu Kredit (Badan Pembinaan Hukum Nasional 1994).

Matsuura, Jeffrey H., Digital Currency: An International Legal and Regulatory Compliance Guide (Bentham Science Publishers Ltd. 2016). 
Mishkin, Frederic S., Ekonomi Uang, Perbankan, dan Pasar Keuangan, 8th ed. (Penerbit Salemba Empat 2008).

Muktar, Bustari, Bank dan lembaga Keuangan Lain (Kencana 2016).

Rahardja, Prathama, Uang \& Perbankan (Rineka Cipta 1987).

Solikin dan Suseno, Uang: Pengertian, Penciptaan dan Peranannya dalam Perekonomian (Pusat Pendidikan dan Studi Kebanksentralan (PPSK) Bank Indonesia 2002).

Subekti, R., Hukum Perjanjian (Intermasa 1987).

Suyatno, Thomas, et al., Kelembagaan Perbankan (Gramedia Pustaka Utama, Jakarta 1988).

Swan, Melanie, Blockchain (O’Reilly Media, Inc. 2015).

Wijaya, Dimaz Ankaaa, et al., Mengenal Bitcoin dan Cryptocurrency (Puspantara 2016).

\section{Laman}

Bank Indonesia, 'Sistem Pembayaran di Indonesia' <https://www.bi.go.id/id/ sistem-pembayaran/di indonesia/Contents/Default.aspx $>$.

'Perkembangan Uang Beredar' $<$ https://www.bi.go.id/id/ publikasi/perkembangan/Default.aspx>.

Blockchain, 'Blockchain Wallet Users' < https://blockchain.info/charts/my-wallet n-users?timespan $=$ all $>$.

Blockchain, 'Market Price' $<$ https://blockchain.info/charts/marketprice?timespan $=2$ years $>$.

Fatimah Salsabila, 'Hukumpedia: "Bitcoin dalam Perspektif Yuridis di Indonesia' $<$ http://www.hukumonline.com/berita/baca/lt5a4f42e32269a/Bitcoin-dalamperspektif-yuridis-di-indonesia-oleh--fatimah-salsabila $>$.

\section{Jurnal}

Firnandes, Fadly dan Rosyetti Rahmat, Richard, 'Pengaruh Uang Giral dan Uang Kuasi terhadap Inflasi di Indonesia'(2014) 1 Jom FEKON.

Mulyanto, Ferry, 'Pemanfaatan Cryptocurrency Sebagai Penerapan Mata Uang 
Rupiah Kedalam Bentuk Digital Menggunakan Teknologi Bitcoin' (2015) 4 Indonesian Journal on Networking and Security.

Somadiyono, Sigit, 'Relevansi UU No. 7 Tahun 2011 Tentang Mata Uang Dengan Fenomena Munculnya Mata Uang Virtual, Studi Kasus Fenomena Bitcoin Di Indonesia' (2014) 14 Jurnal Ilmiah Universitas Batanghari Jambi.

Tampi, Mariske Myeke, 'Legal Protection For Bitcoin Investors In Indonesia: To Move Beyond The Current Exchange System' (2017) 1 Jurnal Hukum \& Pembangunan 47.

\section{Majalah}

Bank Indonesia, "Mengurangi Ketergantungan pada Uang Tunai”, Gerai Indo Bank Indonesia, Edisi 50 Tahun 5 (Bank Indonesia 2014).

\section{Perundang-undangan}

Undang-Undang Nomor 7 Tahun 2011 Tentang Mata Uang, (Lembaran Negara Republik Indonesia Tahun 2011 Nomor 64, Tambahan Lembaran Negara Republik Indonesia Nomor 5223).

Peraturan Bank Indonesia Nomor 18/40/2016 Tentang Penyelenggaraan Pemrosesan Transaksi Pembayaran, (Lembaran Negara Republik Indonesia Tahun 2016 Tahun 236, Tambahan Lembaran Negara Republik Indonesia Nomor 5945).

Peraturan Bank Indonesia Nomor 11/12/PBI/2009 Tentang Uang Elektronik (Electronic Money), (Lembaran Negara Republik Indonesia Tahun 2009 Nomor 65, Tambahan Lembaran Negara Republik Indonesia Nomor 5001).

Siaran Pers Pernyataan Bank Indonesia Terkait Bitcoin dan Virtual Currency No. 16/6/DKom pada tanggal 6 Februari 2014. 
--halaman ini sengaja dibiarkan kosong-- 